\title{
Torsion of dermoid cyst in a perimenopausal woman: a case report
}

\section{Kondareddy Radhika*, Sonam Singh, Munikrishna M.}

Department of Obstetrics and Gynecology, Sri Devaraj Urs Medical College, Kolar, Karnataka, India

Received: 28 July 2018

Accepted: 01 September 2018

\section{*Correspondence:}

Dr. Kondareddy Radhika,

E-mail: radhi.konda91@gmail.com

Copyright: () the author(s), publisher and licensee Medip Academy. This is an open-access article distributed under the terms of the Creative Commons Attribution Non-Commercial License, which permits unrestricted non-commercial use, distribution, and reproduction in any medium, provided the original work is properly cited.

\begin{abstract}
Mature cystic teratoma comprise $20-30 \%$ of all ovarian tumours. They are mostly seen in patients between 20 and 40 years of age and are mostly asymptomatic. Incidence of malignancy is high in perimenopausal and postmenopausal group. Here, authors report a case of torsion of dermoid cyst presenting unusually in a 45-year-old perimenopausal woman with acute abdomen. A 45-year-old perimenopausal woman presented with lower abdominal pain of 8 hours duration and 3-4 episodes of vomiting. Abdominal examination revealed a regular, firm to cystic, tender abdominopelvic mass corresponding to the size of 28 weeks gravid uterus by palpation. Abdominal ultrasonography revealed the presence of right ovarian cyst measuring $12.9 \times 12.8 \times 10.1 \mathrm{~cm}$. Total abdominal hysterectomy with bilateral salpingo oopherectomy was done. Histopathological examination confirmed mature cystic teratoma. Although mature cystic teratoma is rare after 40 years age, especially in perimenopausal women and are usually malignant in that age group, it can have an unusual age presentation at 45 years with benign nature as in present case.
\end{abstract}

Keywords: Perimenopausal, Teratoma, Torsion

\section{INTRODUCTION}

Germ cell tumors are derived from primordial germ cells of the ovary. Approximately $25-30 \%$ of all ovarian tumors are of germ cell origin and of these, $95 \%$ are benign and only $3-4 \%$ are malignant. ${ }^{1}$ Benign cyst teratomas (dermoid cyst) account for 10 to $20 \%$ of all ovarian neoplasms. ${ }^{2}$ They are common in young women, especially at the age of 30 years. Additionally, they are also the most common ovarian cysts in adolescents. ${ }^{3}$ It is quite uncommon in older ages, particular in postmenopausal women. Only a few cases of postmenopausal immature teratoma of the genital tract have been reported so far. ${ }^{4,5}$ In most of cases, they are asymptomatic and can be discovered accidentally on clinical examination or ultrasonographic scan. ${ }^{6}$

Dermoid cysts are usually indolent tumors with very slow rate of growth about $1.8 \mathrm{~mm}$ per year. ${ }^{7}$ Giant dermoid cysts have been infrequently reported in the literature. The incidence of torsion in a case of dermoid cysts is approximately $15 \%$. Ovarian torsion is the fifth most common gynecological emergency condition. ${ }^{8}$ with a prevalence of $2.7 \%$. Adnexal torsion involves twisting or rotation of the ovarian vascular pedicle i.e. the infundibulopelvic ligament, ovary, fallopian tube, or both. ${ }^{9}$ Any delay in diagnosis and prompt treatment can lead to ischemia, necrosis with peritonitis, non-viable ovarian tissue, and in neglected cases may lead to death. Early diagnosis and prompt surgical intervention are vital to preserve ovarian function.

\section{CASE REPORT}

In June 2018, a 45-year- old lady presented to the emergency unit of R. L. JALLAPA Hospital, with acute lower abdominal pain of 8 hours duration which was dull aching, mainly localized to the right side of the abdomen 
and radiating to the back. It was associated with three episodes of vomiting, non-bilious. She had two term normal vaginal deliveries. Her medical, surgical and family history were unremarkable, and her menstrual cycles were regular.

On general examination, she was of well built, weighed $76 \mathrm{~kg}$, BMI of $26.8 \mathrm{~kg} / \mathrm{m}^{2}$. Her blood pressure was $100 / 70$ $\mathrm{mmHg}$, pulse rate was $90 / \mathrm{min}$, regular. There was no pallor. Cardiac and lung examinations were unremarkable. Abdominal examination revealed a grossly distended abdomen by an abdomino-pelvic mass corresponding to the size of 24 weeks gravid uterus by palpation. The mass was regular, variable in consistency, with limited mobility and rebound tenderness was present. On Bimanual examination a mass of size about $15 \times 15 \mathrm{cms}$ firm to cystic in consistency, very tender with limited mobility and smooth surface felt in anterior and right lateral fornix. uterus felt separately from mass, six weeks in size. Right forniceal fullness and tenderness present. Provisional diagnosis of torsion of right ovarian cyst made.

Abdominal ultrasonography revealed the presence of large mixed echogenic solid, cystic and fat components within the lesion measuring $12.9 \times 12.8 \times 10.1 \mathrm{~cm}$ with thin echogenic septum and calcification in right ovary. The fat fluid level noted which moves on lateral decubitus position. Left ovary normal in size and echo pattern. Liver, spleen, appendix, bowel unremarkable.

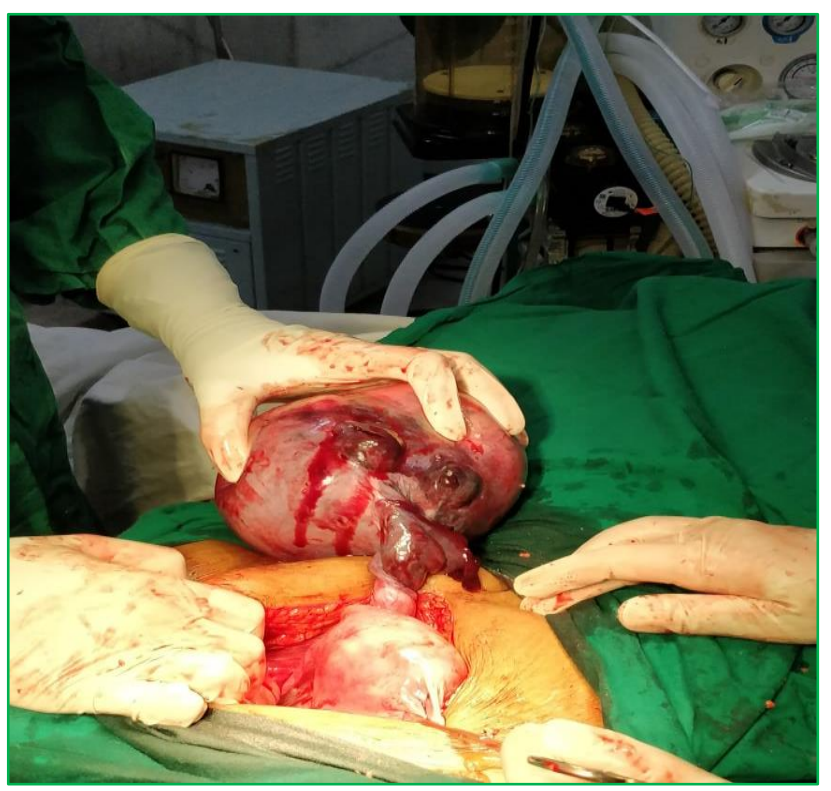

Figure 1: Dermoid cyst of right ovary on laparotomy.

Laboratory investigations, including hemoglobin level, platelet count, urine routine were all within normal range. Based on high suspicion of possibility of twisted ovarian cyst, the patient and her husband were counseled and an informed written consent for abdominal exploration was obtained. Abdominal exploration was done under spinal anesthesia through a vertical incision.
There was a heterogeneous mass originating from the right ovary not adherent to the surrounding viscera with repeated twists in its pedicle (Figure 1). Pedicle containing infundibulopelvic ligament, fallopian tube, round ligament. Total abdominal hysterectomy with bilateral salpingo opherectomy was done. The removed mass measured $15 \times 15 \mathrm{~cm}$. Left ovary and tube were normal, uterus of 6 weeks size. Closure of the abdomen was done in anatomical layers. No blood transfusion was needed. Post operatively, the patient was stable, and the course of recovery was unremarkable.

Histopathological examination revealed twisted dermoid cyst (Figure 2). On gross examination a right ovarian cyst of size $14 \times 9 \times 7 \mathrm{~cm}$ filled with grey white cheesy material along with few hairs. Cut section shows pultaceous material with hair, inner surface of ovary shows hemorrhagic areas and tooth also identified.

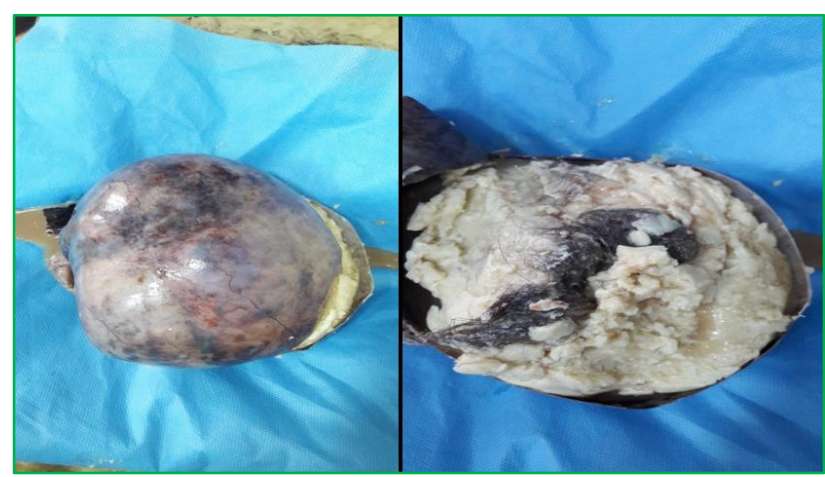

Figure 2: Dermoid cyst of $15 \times 15 \mathrm{~cm}$; cut specimen revealed teeth, hair, and thick sebaceous material.

On microscopy ovary shows ovarian stroma, tissue lined by stratified squamous epithelium, sub epithelium shows sebaceous glands, smooth muscle bundles, foci of respiratory epithelium and mature cartilage are seensuggestive of mature teratoma (Figure 3).

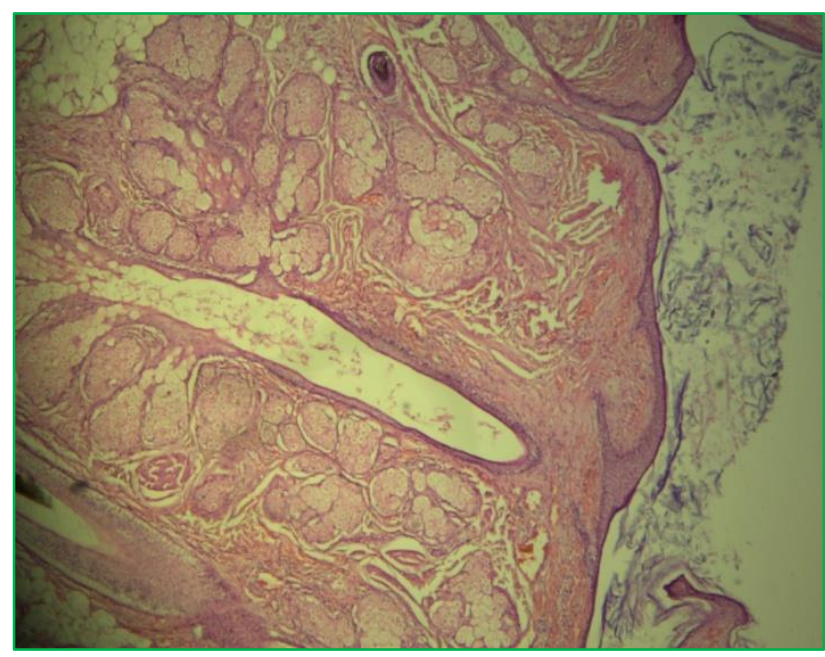

Figure 3: Ovary shows ovarian stroma, lined by stratified squamous epithelium and sebaceous glands. 


\section{DISCUSSION}

Benign cystic teratomas, commonly known as dermoid cysts, are the most common ovarian neoplasms found in women. These neoplasms originate from primordial germ cells that migrate from the yolk sac to the ovary. Teratomas are characterized by the presence of all three embryonic germ cell layers (ectoderm, mesoderm, and endoderm).

Ovarian torsion commonly occurs on the right side. Most commonly, it occurs with torsion of the fallopian tube as they share the same vascular pedicle, as same reported with present case. ${ }^{10}$ Torsion occurs in about $15 \%$ of dermoid cysts as a result of their high fat content, and pultaceous material along with bony tissue and teeth which makes the cyst heavy causing them to freely float in the abdominal cavity, leading to torsion of the adnexa. Torsion causes tissue ischemia and necrosis leading to severe pain; and requires emergency surgical intervention.

Ultrasound is the primary mode of evaluation of a patient with lower abdominal pain because it is noninvasive, accessible, and cost-effective with accurate results. With Ultrasound, the typical findings of ovarian torsion can be visualized in patients of all ages, although they are not always present. One series studying the effectiveness of Ultrasound in diagnosing ovarian torsion yielded a positive predictive value of $87.5 \%$ and specificity of $93.3 \%$, corroborating the potential for expeditiously making this diagnosis. ${ }^{11}$ Features of Ovarian Torsion on ultrasound are:

- Unilateral enlarged ovary $(>4 \mathrm{~cm})^{*}$

- String of pearls sign

- Coexistent mass within the twisted ovary

- Free pelvic fluid

- Twisted vascular pedicle.

However, the presence of normal appearing ovaries does not rule out the diagnosis of adnexal torsion. ${ }^{12}$

At color Doppler sonography of the twisted vascular pedicle, visualization of circular or coiled vessels is the whirlpool sign. Ovaries without flow in the vascular pedicle at color Doppler sonography were necrotic or infarcted at surgery. ${ }^{13,14}$

Doppler sonography does not rule out ovarian torsion. A review of the literature revealed. the presence of normal arterial and venous flow in 57\% (16 out of 28) of cases of surgically confirmed adnexal torsion. ${ }^{15}$ Possible explanations for these observations include: venous thrombosis resulting from torsion leads to symptoms and ovarian necrosis before arterial thrombosis occurs, and persistent adnexal arterial flow is related to the dual ovarian arterial blood supply (ovarian artery and branches from the uterine artery). ${ }^{16}$
Once diagnosis of dermoid cyst with torsion is made, immediate surgery is indicated. Laparoscopy may confirm the diagnosis and permit detorsion of a partial adnexal torsion and excision of the teratoma. Salpingooophorectomy of necrosed adnexa due to complete torsion is possible through a laparoscopic approach if the teratoma is smaller than $5 \mathrm{~cm}$.

Large teratomas, as found in the patient described here, require laparotomy through an abdominal incision, clamping of the torsed pedicle proximal to the torsion and removal of affected adnexa.

This case highlights the rare but possible presentation of dermoid cysts in perimenopausal age.

Funding: No funding sources

Conflict of interest: None declared

Ethical approval: Not required

\section{REFERENCES}

1. Shia Salem. The uterus and adnexa. In: Rumack CM, Wilson SR, eds. Diagnostic ultrasound. $2^{\text {nd }}$ ed, $1^{\text {st }}$ vol; 1998:558.

2. Wittich AC. Adnexal torsion presenting as an acute abdomen in a patient with bilateral cystic teratoma of the ovary. Am Osteopath Assoc. 2002;102(4):231-3.

3. Outwater EK, Siegelman ES, Hunt JL. Ovarian teratomas: tumor types and imaging characteristics. Radiographics. 2001;21(2):475-90.

4. Ornvold K, Detlefsen GU, Horn T, Rorth M. Immature ovarian teratoma in a postmenopausal woman. Acta Obstet Gynecol Scand. 1987;66:473-6.

5. Doss BJ, Jacques SM, Qureshi F, Chang $\mathrm{CH}$, Christensen $\mathrm{CW}$, Morris RT, et al. Immature teratomas of the genital tract in older women. Gynecol Oncol. 1999;73:433-8.

6. Laufer M, Goldstein D. Benign and malignant ovarian masses. In: Emans S, Laufer M, Goldstein D, eds. Pediatric and Adolescent Gynecology, vol 5. Philadelphia: Lippincott Williams and Wilkins; 2005:706-710.

7. Caspi B, Appelman Z, Rabinerson D, Zalel Y, Tulandi T, Shoham Z. The growth pattern of ovarian dermoid cysts: a prospective study in premenopausal and postmenopausal women. Fertil Steril. 1997;68:501-5.

8. Hibbard LT. Adnexal torsion. Am J Obstet Gynecol. 1985;152:456-61.

9. Nichols DH, Julian PJ. Torsion of the adnexa. Clin Obstet Gynecol. 1985;28:375-80.

10. Cass DL, Hawkins E, Brandt ML, Chintagumpala M, Bloss RS, Milewicz AL, et al. Surgery for ovarian masses in infants, children, and adolescents: 102 consecutive patients treated in a 15 -year period. $\mathbf{J}$ Pediatr Surg. 2001;36:693-9.

11. Graif M, Itzchak Y. Sonographic evaluation of ovarian torsion in childhood and adolescence. AJR Am J Roentgenol. 1988;150(3):647-9. 
12. Shadinger LL, Andreotti RF, Kurian RL. Preoperative sonographic and clinical characteristics as predictors of ovarian torsion. J Ultrasound Med. 2008;27:7-13.

13. Lee AR, Kim KH, Lee BH, Chin SY. Massive edema of the ovary: imaging findings. AJR Am J Roentgenol. 1993;161(2):343-4.

14. Vijayaraghavan SB. Sonographic whirlpool sign in ovarian torsion. J Ultrasound Med. 2004;23(12):1643-9.

15. Lee EJ, Kwon HC, Joo HJ, Suh JH, Fleischer AC. Diagnosis of ovarian torsion with color Doppler sonography: depiction of twisted vascular pedicle. J Ultrasound Med. 1998;17:83-9.

16. Rosado WM Jr, Trambert MA, Gosnik BB, Pretorius DH. Adnexal torsion: diagnosis by using Doppler sonography. AJR Am J Roentgenol. 1992;159:12513 .

Cite this article as: Radhika K, Singh S, Munikrishna M. Torsion of dermoid cyst in a perimenopausal woman: a case report. Int J Reprod Contracept Obstet Gynecol 2018;7:4321-4. 